\title{
DAMPAK GUNA LAHAN TERHADAP TINGKAT KEMAMPUAN KINERJA JALAN Studi Kasus : Jalan Ahmad Yani Di Kecamatan Kartasura
}

\author{
Taufik Setyawan ${ }^{1}$; Mila Karmilah ${ }^{2}$ \\ Program Studi Perencanaan Wilayah dan Kota Universitas Islam Sultan Agung Semarang ${ }^{1,2)}$
}

\begin{abstract}
The use of land as a trade and service area contributes greatly to the development of urban economic structures, including in the District of Kartasura. Especially Kartasura's market activity which is always developing because it is a place to fulfill primary needs. However, the existence of this market and also the trade and service activities around it are increasingly troubling due to irregularities and disrupting transportation activities around the market. Geographically, Kartasura Subdistrict is quite close to the Surakarta City area (around $10 \mathrm{Km}$ ), and Surakarta City has a very rapid and dense development intensity and has a limited development area, so the development of socio-economic activities tends to move towards the Kartasura SubDistrict area.

Close socio-economic relations with Surakarta City made Kartasura experience rapid development in the growth of new activities along the A. Yani road. Such as education, health, trade and services, industry and office activities. With the growth of new activities along the A Yani road, traffic jams often occur at peak hours. The congestion is due to the mixture between modes of transportation, trade, industry and offices.

The purpose of this study is to identify the performance of the A Yani road, to determine the effect of land use on congestion that occurs. To achieve these objectives, the analysis used is quantitative calculations. By comparing the road conditions at peak and non peak hours on the A Yani road. The method used in this study is analyzing the volume of the road (V) A Yani experiencing congestion, analyzing side barriers, speed, road capacity $(C) A$ Yani, and the level of road service $(V / C)$ A Yani. In addition to the quantitative analysis also conduct qualitative analysis to clarify the quantitative analysis that has been done. So that what is a problem on Jalan A Yani can also be analyzed, what are the factors that cause congestion and finally show conclusions and recommendations of problems.
\end{abstract}

Keywords: Land use, Traffic Congestion

\section{ABSTRAK}

Penggunaan lahan sebagai kawasan perdagangan dan jasa memberikan andil besar dalam pembangunan struktur ekonomi perkotaan,tidak terkecuali di Kecamatan Kartasura. Terutama Aktivitas pasar Kartasura yang selalu berkembang karena merupakan tempat pemenuhan kebutuhan primer. Akan tetapi keberadaan pasar ini dan juga kegiatan perdagangan dan jasa yang ada disekitarnya semakin meresahkan karena ketidakteraturan dan mengganggu kegiatan transportasi disekitar pasar. Secara geografis, Kecamatan Kartasura cukup dekat dengan wilayah Kota Surakarta (sekitar $10 \mathrm{Km}$ ), dan Kota Surakarta memiliki intensitas perkembangan yang sangat pesat dan padat serta memiliki area pengembangan yang terbatas, sehingga perkembangan kegiatan sosial ekonomi cenderung bergerak ke arah wilayah Kecamatan Kartasura.

Hubungan sosial ekonomi yang erat dengan Kota surakarta membuat Kartasura mengalami perkembangan cukup pesat dalam tumbuhnya kegiatan-kegiatan baru yang berada di sepanjang jalan A. Yani. Seperti Kegiatan pendidikan, kesehatan, perdagangan dan jasa, perindustrian serta perkantoran. Dengan tumbuhnya kegiatan-kegiatan baru yang berada di sepanjang jalan A Yani sering mengalami kemacetan pada jam puncak. Kemacetan tersebut karena adanya percampuran antara moda transportasi Perdagangan, perindustrian dan perkantoran.

Tujuan dari studi ini adalah untuk Mengidentifikasi Kinerja jalan A Yani, untuk mengetahui pengaruh penggunaan lahan terhadap kemacetan yang terjadi. Untuk mencapai tujuan tersebut maka analisis yang 
digunakan adalah perhitungan kuantitatif. Dengan membandingkan kondisi jalan pada waktu jam puncak dan non puncak pada jalan A Yani tersebut. Metode yang digunakan dalam studi ini adalah menganalisis volume jalan (V) A Yani yang mengalami titik kemacetan, menganalisis hambatan samping, kecepatan, kapasitas jalan (C) A Yani, dan tingkat pelayanan jalan (V/C) A Yani. Selain dengan analisis kuantitatif juga melakukan analisis kualitatif guna memperjelas analisis kuantitatif yang telah dilakukan. Sehingga apa yang menjadi permasalahan di Jalan A Yani juga dapat dianalisis, apa yang menjadi faktor penyebab kemacetan dan akhirnya menampilkan kesimpulan serta rekomendasi dari permasalahan.

Kata Kunci : Penggunaan lahan, Kemacetan Lalu Lintas 


\section{PENDAHULUAN}

\section{Latar Belakang}

Kondisi dimana tersendatnya atau terhentinya lalu lintas yang diakibatkan oleh jumlah kendaraan yang melebihi dari kapasitas jalan yang tersedia disebut dengan kemacetan lalulintas (Kasikoen dan Atmaja, 2012). Kemacetan lalu-lintas merupakan masalah klasik di kotakota besar apalagi di negara berkembang seperti di Indonesia. Banyak hal yang bisa menjadi penyebab kemacetan lalu-lintas tersebut, sepintas mungkin sama, mungkin juga tidak, setiap tempat atau lokasi bisa berbeda karakteristik, dan faktor-faktor yang mempengaruhi, disamping antara yang direncanakan dan pelaksanaan yang belum tentu sama (implementasi). Menurut Suyuti (2012), kemacetan lalu-lintas yang terjadi pada suatu wilayah umumnya disebabkan karena ketidakseimbangan antara permintaan (demand) dan penawaran (supply) yang beroirentasi pada peningkatan jumlah kendaraan dengan kapasitas prasarana transportasi berupa jaringan jalan dan jaringan angkutan umum. Beberapa dampak yang ditimbulkan dari kemacetan lalu-lintas dapat dilihat dari beberapa aspek meliputi, segi waktu, biaya, dan lingkungan. Jika dilihat dari segi waktu yaitu menyebabkan waktu dalam menempuh perjalanan dari tempat satu ke tempat lainnya menjadi lebih lama dan tidak sesuai dengan perkiraan waktu yang sudah ditentukan. Kemudian, berdasarkan segi biaya menjadikan seseorang yang menempuh perjalanan dengan kendaraan menghabiskan banyak bensin. Sedangkan dari segi lingkungan, kemacetan dapat menimbulkan polusi udara yang pengaruhnya berakibat langsung ke lingkungan sosial (Ekawati dkk, 2013). Sehingga kajian studi dan penelitian terkait kemacetan di jalan, sebaiknya dapat memberikan rekomendasi dan saran untuk dapat mengurangi ataupun menghindarkan dari dampak kerugian kemacetan seperti yang sudah terjadi di kota besar lain.

Apalagi jika kemacetan yang terjadi dikarenakan adanya bergagai macam aktivitas perdagangan dan jasa, seperti aktivitas yang tampak di sepanjang jalan Ahmad Yani memunculkan bangkitan lalu lintas yang kemudian berdampak pada titik-titik sebaran bangkitan pergerakan, sehingga perubahan tersebut memunculkan perubahan pada pola kondisi arus jaringan jalan dan kebutuhan sarana pergerakan, akan berbanding bila terjadi peningkatan sarana dan prasarana transportasi memberikan dampak pola pemanfaatan ruang aktivitas ditandai dengan tumbuhnya kawasan pertokoan (ruko), aktivitas industri dan aktivitas 
lainnya seperti pasar, mini market,toko kelontong, warung makan, bengkel yang berada di jalan utama yang menghubungkan Kartasura-solo tersebut.

Kemacetan pada dasarnya terjadi akibat menurunnya kinerja suatu penggal jalan yakni peningkatan volume lalu-lintas yang melebihi daya tampung (kapasitas) jalan yang seharusnya. Namun berdasarkan observasi lapangan sementara, kemacetan lalu-lintas di jalan Ahmad Yani terjadi karena dipengaruhi oleh beragam faktor yang saling terkait seperti adanya aktivitas perdagangan (ruko), dan aktivitas lainnya, keberadaan simpul/persimpangan, dan perilaku pemakai jalan.

Kemacetan yang terjadi karena adanya aktivitas dan percampuran antar arus lokal dan regional. Oleh karena itu untuk mengurangi beban kinerja jalan Ahmad Yani maka perlu adanya perencanaan yang lebih matang. Diharapkan adanya rekomendasi untuk akan memecah permasalahan kemacetan tidak berlangsung secara terus menerus.

Berdasarkan perkembangannya, kemacetan sering terjadi di kawasan perkotaan hal tersebut terjadi karena beberapa faktor yang mempengaruhi antara lain penggunaan lahan di sekitar jalan tersebut, kepadatan penduduk dan kondisi jalan dapat menjadi faktor yang dapat mengindikasikan permasalahan kemacetan di kawasan tersebut. karena jalan Ahmad Yani merupakan jalan utama Kartasura-Solo, di jalan ini sering dilalui beranekaragam kendaraan dan para pengguna lain yang hendak bepergian ketempat lain. Oleh sebab itu jalan Ahmad Yani rawan sekali terjadi kemacetan.

\section{METODOLOGI}

Dalam penelitian ini, menggunakan deskriptif kuantitatif, deskriptif memberikan narasi yang dapat menghubungkan keterkaitan suatu objek, kejadian maupu fenemona yang ada di lapangan. Surachmad (dalam Singarimbun, 1995), menyatakan bahwa penelitian deskriptif sebagai upaya problem solving dengan menyajikan dan mengidentifikasi fenomena yang muncul, selanjutnya proses analisis diolah berdasarkan hasil-hasil temuan yang didapat. Kuantitatif, menjadi langkah dan koridor dalam membaca hasil analisis dengan menggunakan parameter yang terukur. Sehingga, pendekatan deskriptif digunakan sebagai upaya memvisualisasikan atau menarasikan eksisting kawasan hingga menarasikan perkembangan yang akan terjadi di kawasan, kondisi ini diarahkan dalam koridor kuantitatif sebagai media analisis kapasitas dan kinerja jalan. 


\section{Sistem Transportasi}

Transportasi adalah sarana bagi manusia untuk memindahkan sesuatu, baik manusia atau benda dari satu tempat ke tempat lain, dengan ataupun tanpa mempergunakan alat bantu. (Salim, H. A. Abbas. 1993:5) Alat bantu tersebut dapat berupa tenaga manusia, binatang, alam ataupun benda lain dengan mempergunakan mesin ataupun tidak bermesin. Terdapat 3 unsur utama transportasi yakni:

a. Ada yang dipindahkan yaitu benda/barang, manusia, informasi.

b. Ada yang (mempermudah) memindahkan yaitu sarana, antara lain: kendaraan, kereta api, kapal laut, pesawat.

c. Ada yang memungkinkan terjadinya perpindahan yaitu prasarana, antara lain: jalan, jembatan, pelabuhan, terminal, bandara.

\section{Hubungan Tata Guna Lahan Dengan Transportasi}

Guna lahan berkaitan erat dengan kegiatan (aktivitas) manusia. Jadi, sebenarnya guna lahan dibentuk oleh tiga unsur, yaitu manusia, aktivitas dan lokasi yang saling berinteraksi satu sama lain (Mayer \& Miller, 1984). Sebagai individu yang memiliki sifat dinamis, manusia memunculkan aktivitas-aktivitas yang dihasilkan. Sehingga memerlukan ruang sebagai lokasi berbaurnya aktivitas yang muncul. Ruang aktivitas dengan daya tampung tinggi ini biasanya berbentuk lahan industri, yang kemudian akan diikuti oleh peningkatan kegiatan lalu lintas yang muncul akibat guna lahan tersebut. Potensi ruang diperkotaan dapat diukur dari pemanfaatan lahan pada lingkungan sekitar. Berbagai variasi guna lahan memiliki klasifikasi sendiri, secara umum di bagi menjadi empat yaitu permukiman, jaringan transportasi, kegiatan industri/komersial, dan fasilitas pelayanan umum (Mayer \& Miller, 1984).

Menurut Sukarto (2006) bahwa hubungan yang sangat erat yang dimiliki antara transportasi dan tata guna lahan yang biasanya disebut dengan terbentuknya system transportasi guna lahan. Apabila penggunaan lahan dapat tercipta ideal seharusnya keperluan akan transportasi juga harus terpenuhi dengan baik pula. Namun, jika kondisi lalu lintas yang tertundak pastinya juga menganggu kegiatan yang ada pada tata guna lahannya, kemudian jika transportasi tidak dapat melayani penggunaan lahan maka akan sia-sia atau dikatakan tidak bermanfaat. 
Secara umum jaringan jalan dapat dikelompokkan berdasarkan struktur jaringannya (Bambang I.S dan Undang-undang No.3 Tahun 1980 tentang Jalan dalam Miro, 1997:52), yaitu:

1. Jaringan jalan berdasarkan Sistem (pelayanan penghubung) :

a) Sistem jaringan Jalan Primer, adalah sistem jaringan jalan yang menghubungkan kota atau wilayah di tingkat nasional atau dalam pengertian lain ruas-ruas (link-link) yang menghubungkan simpul-simpul jasa distribusi yang kemudian berwujud kota di tingkat nasional.

b) Sistem jaringan Jalan Sekunder, adalah sistem jaringan jalan yang menghubungkan zona-zona dan kawasan-kawasan (titik-titik simpul) di dalam kota.

2. Jaringan jalan berdasarkan Peran (fungsi) :

a) Jalan Arteri, adalah jalan yang melayani angkutan jarak jauh dengan kecamatan ratarata tinggi dan jumlah jalan masuk (access road) dibatasi secara efisien.

b) Jalan Kolektor, adalah jalan yang melayani angkutan jarak sedang (angkutan pengumpul/pembagi) dengan kecepatan rata-rata sedang dan jumlah jalan masuk (access road) masih dibatasi.

c) Jalan Lokal, adalah jalan yang melayani angkutan jarak dekat (angkutan setempat) dengan kecepatan rata-rata rendah dan jumlah jalan masuk (access road) tidak dibatasi.

3. Jaringan jalan berdasarkan Peruntukkan :

a) Jalan Umum, adalah jalan yang diperuntukkan untuk lalu-lintas umum.

b) Jalan Khusus, adalah jalan yang diperuntukkan untuk lalu-lintas selain dari jalan umum, seperti jalan di kompleks perkebunan, kehutanan, pertambangan, kompleks hankam, jalan pipa dan jalan inspeksi (irigasi dan gas).

4. Jaringan jalan berdasarkan Klasifikasi Teknis :

a) Jalan Kelas I; yaitu jalan arteri yang dapat dilalui kendaraan bermotor termasuk muatan dengan ukuran tidak melebihi 2.500 milimeter, ukuran panjang tidak melebihi 18.000 milimeter, dan muatan sumbu terberat yang diijinkan lebih besar dari 10 ton.

b) Jalan Kelas II; yaitu jalan arteri yang dapat dilalui kendaraan bermotor termasuk muatan dengan ukuran lebar tidak melebihi 2.500 milimeter, ukuran panjang tidak melebihi 18.000 milimeter, dan muatan sumbu terberat yang diijinkan adalah 10 ton. 
c) Jalan Kelas IIIA; yaitu jalan arteri atau kolektor yang dapat dilalui kendaraan bermotor termasuk muatan dengan ukuran lebar tidak melebihi 2.500 milimeter, ukuran panjang tidak melebihi 18.000 milimeter, dan muatan sumbu terberat yang diijinkan adalah 8 ton.

d) Jalan Kelas III B; yaitu jalan kolektor yang dilalui kendaraan bermotor termasuk muatan dengan ukuran lebar tidak melebihi 2.500 milimeter, ukuran panjang tidak melebihi 12.000 milimeter, dan muatan sumbu terberat yang diijinkan adalah 8 ton.

e) Jalan Kelas III C; yaitu jalan lokal yang dapat dilalui kendaraan bermotor termasuk muatan dengan ukuran lebar tidak melebihi 2.100 milimeter, ukuran panjang tidak melebihi 9.000 milimeter, dan muatan sumbu terberat yang diijinkan adalah 8 ton.

\section{HASIL DAN PEMBAHASAN}

Kecamatan Kartasura merupakan salah satu dari 12 kecamatan yang dimiliki oleh Kabupaten Sukoharjo yang terletak di bagian utara kabupaten dan secara geografis terletak

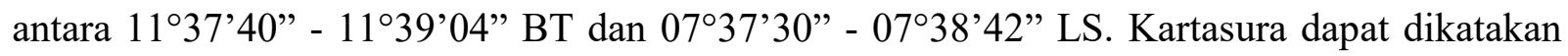
merupakan kota satelit bagi Kota Surakarta atau Solo. Selain itu Kecamatan Kartasura juga merupakan salah satu wilayah atau jalur alternatif yang menghubungkan Kabupaten Boyolali dengan Kota Surakarta serta sebagai pintu gerbang kawasan segitiga Yogya-Semarang-Solo. Kecamatan kartasura memiliki berbagai penggunaan lahan yang bermacam-acam. Pola tata guna lahan terdiri dari permukiman, komersiil, industry, militer, pertanian dan penggunaan lainnya seperti yang dijelaskan dibawah ini :

1. Permukiman

Penggunaan lahan di Kecamatan Kartasura yang didominasi oleh lahan pemukiman memiliki luasan mencapai $820.95 \mathrm{Ha}$ atau $42.69 \%$ dari total luas wilayah Kecamatan dengan desa/kelurahan Makamhaji memiliki lahan permukiman yang paling luas yakni dengan $128.18 \mathrm{Ha}$ atau $15.61 \%$ dari luas lahan permukiman keseluruhan. Kondisi tersebut pada perkembangannya terus mengalami perubahan karena penggunaan lahan untuk permukiman semakin bertambah seiring dengan adanya peningkatan jumlah penduduk di Kecamatan Kartasura. 


\section{Industri}

Kegiatan industri di Kecamatan Kartasura terdiri atas industri tekstil, mebel, kertas dan jasa logistik yang dibedakan berdasarkan PMA (Penanaman Modal Asing) dan PMDN (Penanaman Modal Dalam Negeri). Selain itu juga terdapat home industri berupa pengrajin tahu yang berada di Kelurahan Kartasura (Dukuh Purwogondo), Desa Wirogunan dan Desa Ngabeyan (Dukuh Brontowiryan).

3. Komersiil ( perdagangan dan jasa )

Sebagai wilayah yang berdekatan dengan kota/kabupaten sekitar, Kecamatan Kartasura mempunyai kegiatan perdagangan dan jasa yang banyak tersebar di wilayahnya terutama pada lokasi-lokasi yang berdekatan dengan jalan utama selain itu berdasarkan observasi lapangan, sebagian kecil wilayah Kecamatan Kartasura juga dipakai kegiatan perdagangan jasa oleh Kota Surakarta yang sangat berdekatan wilayahnya dengan Kecamatan Kartasura. Kegiatan perdagangan dan jasa yang ada diantaranya adalah pasar, minimarket, toko kelontong, warung makan, bengkel, wartel, pusat perbelanjaan, ruko, dll. Lahan untuk kegiatan komersiil ini sebagian besar terletak di sepanjang jalan utama yang menghubungkan Kartasura-Solo serta jalan arah menuju ke Bandara.

4. Pertanian

Area pertanian di Kecamatan Kartasura terdiri dari pertanian lahan basah dan pertanian lahan kering. Pertanian lahan basah mendominasi area pertanian di Kecamatan Kartasura dengan luasan mencapai 550.83 Ha atau 28.64\% dari total luas Kecamatan Kartasura.

5. Militer

Kawasan khusus militer di Kecamatan Kartasura terletak di Desa Pucangan. Kawasan khusus militer untuk KOPASUS atau yang biasa disebut Kandang Menjangan oleh masyarakat ini termasuk asrama militer serta lahan yang masih berupa sawah. Luas penggunaan lahan untuk kawasan militer ini adalah sebesar 54.27 Ha.

Pola jaringan jalan di Kecamatan Kartasura terbentuk menurut pola jaringan jalan utama yang ada yang berfungsi sebagai jaringan induknya (root), yaitu sesuai dengan karakter fisik wilayahnya yang merupakan kawasan yang relatif datar, sehingga pola jaringan jalan utama ini berbentuk lurus, dan begitu pula dengan pola jaringan jalan lingkungannya cenderung berpola sesuai dengan pola jalan induknya dengan banyak persimpangan yang membentuk pola grid. Sementara itu ditinjau dari fungsinya, jalan utama pada lokasi studi 
yaitu Kecamatan Kartasura meliputi jalan Arteri Primer, Kolektor Sekunder serta Lokal Primer. Berikut rincian mengenai jaringan jalan di Kecamatan Kartasura:

1. Jalan yang menghubungkan antara Kota Surakarta dengan Kabupaten Boyolali yang melewati jalur jalan utama Kecamatan Kartasura serta jalan yang menghubungkan Kecamatan Kartasura ke Kabupaten Klaten adalah berfungsi Arteri Primer.

2. Jalan dari jaringan jalan utama (Arteri Primer) yang menghubungkan dengan Bandara Adisumarmo, dan jalur jalan yang sejajar dengan jalur jalan yang menghubungkan Kota Surakarta dengan Kabupaten Boyolali, menuju ke Kota Surakarta adalah berfungsi sebagai Kolektor Sekunder.

3. Jalur jalan yang menghubungkan antara jalur Arteri Primer dengan Kolektor Sekunder yang menuju Bandara Adisumarmo dan jalur jalan utama yang menghubungkan antar Desa/Kelurahan berfungsi Lokal Primer

Selain itu, terdapat pula fungsi jalan lingkungan/ lainnya yang merupakan jalan lokal sekunder dengan tipe yang lebih kecil yang menghubungkan pusat-pusat kegiatan lokal antar blok lingkungan.

Jalan A Yani merupakan jalan arteri primer yamg merupakan jalan penghubung antara kartasura dengan kota Solo. Di penggal jalan A Yani memiliki lebar jalan \pm 10 meter, tidak memiliki median jalan. Jalan tersebut memiliki 2 arah pergerakan dan aktivitas perangkutan yang tinggi dan padat dikarenakan terdapat kegiatan perdagangan dan jasa, berupa pasar dan sering terjadi kemacetan khususnya pada jam puncak. Ini yang merupakan masalah lalu lintas pada ruas jalan tersebut.

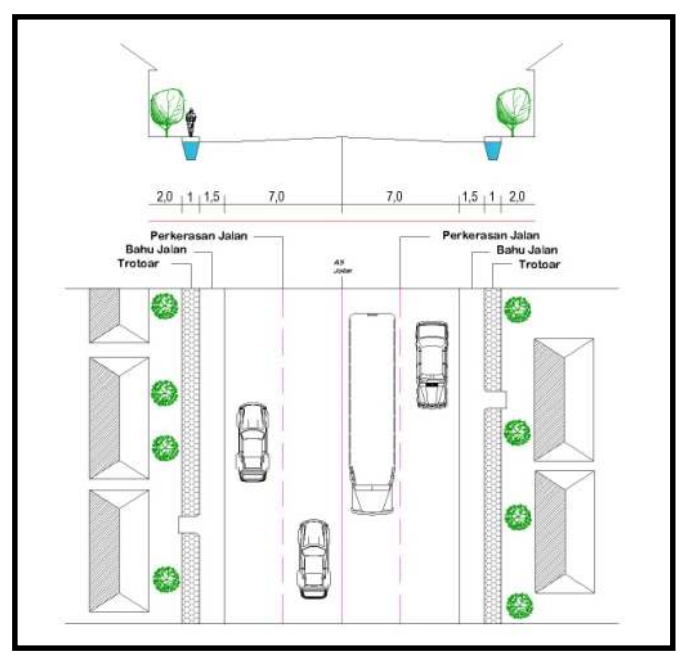


Gambar 1. Penampang Jalan Kawasan Jalan A Yani Kecamatan Kartasura Sumber :Hasil Observasi, 2014

\section{Permasalahan Lalu Lintas Jalan A Yani Katasura}

Kecamatan Kartasura yang merupakan salah satu wilayah atau jalur alternatif yang menghubungkan Kabupaten Boyolali dengan Kota Surakarta serta sebagai pintu gerbang kawasan segitiga Yogya-Semarang-Solo. ini yang membuat di Jalan A Yani Bercampurnya arus lalu lintas tersebut menyebabkan tingginya volume lalu lintas. Hal ini yang mengakibatkan kemacetan di ruas jalan tersebut. Kondisi kemacetan dapat dilihat pada gambar dibawah ini :

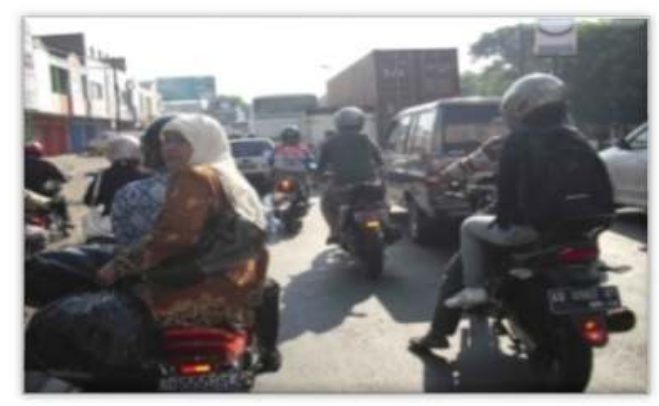

Gambar 2. Kondisi Kemacetan Penggal Jalan A Yani Kecamatan Kartasura Sumber :Hasil Observasi, 2014

\section{Hambatan Samping Jalan A Yani}

Tundaan yang terjadi di jalan A Yani ada beberapa macam tundaan, berupa tundaan tetap ,tundaan operasional dan tundaan akibat gangguan samping. Tundaan tetap, disebabkan oleh peralatan kontrol lalu-lintas dan terutama terjadi pada persimpangan. Penyebabnya adalah lampu lalu-lintas, dan rambu-rambu perintah berhenti. Tundaan operasional tundaan yang disebabkan oleh adanya gangguan di antara unsur-unsur lalu-lintas itu sendiri, tundaan ini berkaitan dengan pengaruh lalu-lintas kendaraan lainnya. Berikut adalah jumlah hambatan samping pada saat jam non puncak maupun pada saat jam puncak pada jalan A Yani akibat adanya berbagai aktivitas yang ada terutama dari aktivitas komersiil yang ada di jalan A Yani.

\section{Analisis Perhitungan Arus Lalu Lintas Pada Penggal Jalan A Yani}

Perhitungan arus lalu lintas digunakan untuk mengetahui tingkat pelayanan penggal jalan A Yani. Analisis perhitungan transportasi dilakukan dengan mengkaji pergerakan transportasi dilaksanakan melalui traffic counting, yaitu pendekatan analisis perhitungan 
pergerakan per satuan waktu pada suatu penggal jalan. kondisi tingkat pelayanan suatu jalan dapat ditinjau melalui dari perbandingan antara volume lalu lintas dengan kapasitas jalan serta kecepatan pada suatu penggal jalan.

Pehitungan volume lalu lintas dilakukan untuk mengetahui beban lalu lintas di penggal jalan A Yani. Perhitungan dilakukan pada jam puncak pagi yaitu 06.30-07.30 yaitu pada saat banyak masyarakat beraktivitas terutama di Pasar Kartasura untuk memenuhi kebutuhan sehari-hari dan jam puncak sore yaitu jam 17.00-18.00 dimana banyak warga yang pulang kerja serta adanya aktivitas lainnya pada sore hari, serta jam non puncak yaitu pada saat masyarakat sedang melakukan aktivitasnya yaitu pada jam 13.00-14.00. Penentuan hari berdasarkan survey dilakukan pada hari kerja dan hari libur. Perhitungan volume lalu lintas dilakukan pada setiap jenis/ type kendaraan yang dihitung sesuai dengan bobot EMP (ekuivalensi mobil penumpang) jenis kendaraan, kemudian dihasilkan berupa satuan SMP (satuan mobil penumpang) dari masing-masing jenis kendaraan. Dimana MC, EMP yang digunakan adalah 0,5 dan untuk HV EMP yang digunakan adalah 1,3. Karena jumlah satuan mobil penumpang $>1800$ kendaraan/jam dan lebar jalur lalu lintas $\geq 6$. Sedangkan untuk LV, EMP yang digunakan adalah tetap yaitu 1.

\section{Analisis Kondisi Sarana dan Prasarana Transportasi Di Penggal Jalan A Yani}

Kelancaran Kegiatan Masyarakat Di penggal jalan A Yani sangat diperngaruhi oleh tersedianya sarana dan prasarana transportasi yang memadai. Jaringan jalan merupakan salah satu prasarana transportasi yang penting bagi perkembangan dan kelancaran aktivitas atau kegiatan masyarakat sehari-hari. Sedangkan moda transportasi yang menjadi sarana penunjang suatu aktivitas.

\section{Analisis Aktivitas dan Tata Guna Lahan}

Kegiatan perdagangan dan jasa di Jalan A Yani bersinggungan langsung dengan jalan utama, lebih lagi karena juga ada kegiatan pasar kartasura. Kegiatan yang berkaitan langsung dengan aktivitas pasar seperti bongkar muat barang dan proses naik turun AUP pengunjung pasar berinteraksi langsung dengan lalu lintas kendaraan di jalan A Yani.

Tata ruang kota (urban spatial structure) adalah wujud struktural dan pola penataan ruang, baik direncanakan atau tidak. Perkotaan menjadi pusat pemukiman dan juga pusat pelayanan (jasa) terhadap penduduk kota maupun penduduk dari wilayah yang menjadi wilayah pengaruhnya (hinterland-nya) akan mempunyai struktur tata ruang tertentu dalam 
rangka penyesuaian terhadap fungsinya untuk mencapai tingkat efiensi pelayanan dan sekaligus kenyamanan lingkungan. Untuk mengetahui perubahan yang terjadi pada penggunaan lahan khusunya blok bangunan berikut ini perbandingan peta blok bangunan penggunaan lahan lokasi studi yang diambil dari foto udara/citra pada tahun 2006, 2009, 2011, dan 2013.

\section{KESIMPULAN DAN SARAN}

\section{Konstans Metode Kinerja Jalan}

Kinerja jalan adalah seberapa besar kemampuan jalan untuk melayani beban diatasnya. Kinerja suatu jalan erat kaitannya dengan tingkat pelayanan jalan untuk melayani beban jalan tersebut. Dapat dikatakan pula bahwa kinerja suatu jalan dilihat melalui tingkat pelayanan jalan tersebut.

Berdasarkan analisis kinerja ruas Jalan A Yani terhadap kemacetan yang terjadi dapat dilihat dari volume lalu lintas kapasitas, kecepatan arus bebas, serta tingkat pelayanan Jalan, dengan membandingkan pada kondisi non puncak maupun pada kondisi puncak pagi dan sore dihasilkan output sebagai berikut :

1. Dampak Pengaruh penggunaan lahan terhadap volume lalu lintas pada jam pucak pagi terhadap jam non puncak yaitu mengalami kenaikan sebesar 47,2 \% atau sebesar 1825 smp/jam dan mengalami kenaikan sebesar 44,3 \% atau sebesar $1663 \mathrm{smp} /$ jam pada saat kondisi jam puncak sore. Hal ini terjadi karena tingginya bangkitan di ruas Jalan A Yani.

2. Dampak penggunaan lahan sebagai kawasan perdagangan dan jasa terhadap Kapasitas Jalan pada ruas Jalan A yani yaitu mengalami penurunan sebesar 12,7\% atau sebesar 699 smp/jam.

3. Dampak Penggunaan lahan sebagai kawasan perdagangan dan jasa terhadap kecepatan lalu lintas ruas Jalan A yani yaitu menurunkan kecepatan sebesar 40\% atau sebesar 12,4 mil/jam pada jam puncak pagi dan menurunkan kecepatan sebesar 20\% atau sebesar 6,2 mil/jam pada jam puncak sore.

4. Dampak Penggunaan lahan sebagai kawasan perdagangan dan jasa terhadap tingkat pelayanan Jalan (LOS) pada ruas Jalan A Yani yaitu mengalami penurunan tingkat pelayanan Jalan (LOS) sebesar 53,8\% pada jam puncak pagi dan 61,5\% pada jam puncak sore, dimana pada jam non puncak berada dalam kategori A, pada jam puncak pagi berada pada kategori D sedangkan pada jam puncak sore berada pada kategori C. 
Dari analisis Pengaruh penggunaan lahan terhadap kemacetan di Jalan A Yani dapat disimpulkan bahwa dengan adanya aktivitas perdagangan dan jasa yang berada di ruas Jalan tersebut menaikkan volume lalu lintas, menurunkan kinerja Jalan A yani, serta kecepatan arus bebas, dan tingkat pelayanan Jalan, sehingga menimbulkan kemacetan.

\section{Metode Perhitungan Kinerja Jalan}

Kelebihan dari metode :

$\checkmark$ Kelebihan dalam penggunaan metode kinerja Jalan yaitu dapat mengetahui tingkat pelayanan suatu Jalan apakah Jalan tersebut dapat dikatakan macet atau tidak dengan perhitungan kapasitas Jalan, volume kendaraan dan kecepatan kendaraan.

$\checkmark$ Mengetahui seberapa besar kemampuan jalan untuk melayani beban diatasnya.

$\checkmark$ Mengetahui hal-hal yang mempengaruhi kinerja jalan, yaitu waktu perjalanan / kecepatan, keterandalan, kenyamanan, keamanan dan biaya.

Kekurangan dari metode :

$\checkmark$ Kekurangan dalam menggunakan metode kinerja Jalan yaitu data yang dibutuhkan harus kongkret atau fakta dengan observasi langsung sehingga menghabiskan banyak waktu.

$\checkmark$ Dibutuhkan ketepatan perhitungan dalam traffic counting.

$\checkmark$ Belum memberikan solusi yang efektif dalam menyelesaikan masalah kemacetan yang terjadi di suatu ruas jalan.

\section{Rekomendasi}

Rekomendasi yang diajukan berdasarkan kesimpulan yang telah diambil dalam proyek akhir ini adalah :

1. Perlu adanya penataan lalu lintas pada ruas Jalan A Yani. kawasan ini yang sering terjadi kemacetan dengan pengaturan lalu lintas dan sistem perparkiran sehingga ruas Jalan tersebut tidak terjadi kemacetan lagi.

2. Pengaturan aktivitas di sekitar ruas Jalan tersebut juga penting misal penataan adanya pasar Kartasura disekitar ruas Jalan A Yani sehingga tidak mengganggu aktivitas lalu lintas jalan tersebut. Misalnya dengan menambah jalur pembagi sehingga aktivitas perdagangan dan jasa pasar tidak mengganggu jalan.

3. Memperbaiki jembatan penyeberangan orang, sehingga saat menyeberang tidak mengganggu aktivitas lalu lintas Jalan A Yani. 


\section{DAFTAR PUSTAKA}

Mayer \& Miller (1984). Pengaruh Penggunaan Lahan Terhadap Transportasi

Miro, Fidel MSTR. (1997). Sistem Transportasi Kota. Transito. Bandung.

Salim, H. A. Abbas. (1993). Manajemen Transportasi. Raja Garfindo. Persada. Jakartakumala

Ekawati, Natalia Niken. (2013). Kajian Dampak Pengembangan Pembangunan Kota Malang Terhadap Kemacetan Lalu Lintas (Studi pada Dinas Perhubungan Kota Malang). Jurnal Administrasi Publik. 2 (1), 129-133.

Kasikoen, Ken Martina. Atmaja, Syahroni Sukma. (2012). Upaya Penanganan Permasalahan Lalu Lintas di Ruas Jalan Karet Raya Kecamatan Cibodas Kota Tangerang. Jurnal Planesa. 3 (1).

Sukarto, Haryono. (2006). Pemilihan Model Transportasi di DKI Jakarta dengan Analisis Kebijakan "Proses Hirarki Analitik”. Jurnal Teknik Sipil. 3 (1).

Suyuti, Rusmadi. (2012). Impelemntasi “Intelligent Transportation System (ITS)" untuk Mengatasi Kemacetan Lalu Lintas di DKI Jakarta. Jurna Konstruksia. 3 (2). 